Volume 8

Issue 4 - Cancer Screening

Article 6

10-18-2021

\title{
Patient and Clinician Characteristics That Predict Breast Cancer Screening Behavior in 40-49-Year-Old Women
}

Sarina Schrager

Claudia Evaristo

Terry Little

Lori DuBenske

Elizabeth S. Burnside

Follow this and additional works at: https://aah.org/jpcrr

Part of the Community Health and Preventive Medicine Commons, Family Medicine Commons, Internal Medicine Commons, Neoplasms Commons, Oncology Commons, Primary Care Commons, and the Women's Health Commons

\section{Recommended Citation}

Schrager S, Evaristo C, Little T, DuBenske L, Burnside ES. Patient and clinician characteristics that predict breast cancer screening behavior in 40-49-year-old women. J Patient Cent Res Rev. 2021;8:331-5. doi: $10.17294 / 2330-0698.1814$

Published quarterly by Midwest-based health system Advocate Aurora Health and indexed in PubMed Central, the Journal of Patient-Centered Research and Reviews (JPCRR) is an open access, peer-reviewed medical journal focused on disseminating scholarly works devoted to improving patient-centered care practices, health outcomes, and the patient experience. 


\title{
Patient and Clinician Characteristics That Predict Breast Cancer Screening Behavior in 40-49-Year-Old Women
}

\author{
Sarina Schrager, MD, MS, ${ }^{1}$ Claudia Evaristo, BS,${ }^{2}$ Terry Little, MS,${ }^{3}$ Lori DuBenske, $\mathrm{PhD},{ }^{4}$ \\ Elizabeth S. Burnside, MD, MS, $\mathrm{MPH}^{3}$ \\ ${ }^{1}$ University of Wisconsin Department of Family Medicine and Community Health, Madison, WI; ${ }^{2}$ University of Wisconsin \\ School of Medicine and Public Health, Madison, WI; ${ }^{3}$ University of Wisconsin Department of Radiology, Madison, WI; \\ ${ }^{4}$ University of Wisconsin Carbone Cancer Center, Madison, WI
}

\begin{abstract}
Guidelines recommend that clinicians practice shared decision-making (SDM) with women in their 40s to discuss breast cancer screening. Traditionally, SDM includes discussion of values and preferences to help determine a decision that is congruent with what the patient desires. We analyzed 54 women's breast cancer screening decisions after a SDM conversation with their clinician. We looked at both patient and clinician characteristics that predicted whether or not a woman would get a screening mammogram. Women with a family history of breast cancer or who had a previous abnormal mammogram had higher rates of screening. Screening rates also varied widely between clinicians, raising the question of whether clinician attitudes impacted the SDM conversation. (J Patient Cent Res Rev. 2021;8:331-335.)
\end{abstract}

Keywords breast cancer; screening; shared decision-making

$\mathrm{B}$ reast cancer continues to be the most common new cancer diagnosis in women. Mammography screening programs have decreased mortality from breast cancer in women of all ages. The U.S. Preventive Services Task Force has recommended that clinicians use shared decision-making (SDM) with women in their 40s to determine whether their individual risk factors and values support screening. ${ }^{1}$ Due to the low prevalence of breast cancer among women 40-49 years of age and the high occurrence of false positives, the benefit/harm ratio for screening mammography in this age group has prompted calls for risk- and preference-based SDM. Traditionally, SDM includes discussion of values and preferences to help determine a decision that is congruent with what the patient desires.

Clinicians can play an important role in helping women belonging to this borderline age group make an informed decision. Previous data have shown variations in screening practices among primary care clinicians. ${ }^{2,3}$ Use of a decision aid improves patient knowledge of risks and benefits of breast cancer screening but has a variable

Corresponding author: Sarina Schrager, Department of Family Medicine and Community Health, University of Wisconsin, 1110 Delaplaine Ct., Madison, WI 53715 (sbschrag@wisc.edu) effect on screening rates. ${ }^{4}$ This study reviewed data from a breast cancer screening SDM project targeting women in their 40s and evaluated whether there were patient or clinician factors that predicted whether or not a woman would get a screening mammogram.

\section{METHODS}

This prospective study took place across 4 different primary care practices within UW Health (the health system for the University of Wisconsin-Madison). Patients and clinicians both were asked to consent to study participation, which included audiotaping of a regularly scheduled well-woman exam visit (during May 2017-May 2018). Patients were excluded if they had had breast cancer or if they had already had a mammogram within the 12 months prior to the visit. The research team evaluated patient characteristics using the self-reported data from a patient survey completed at the visit as part of the study, collected clinician demographics from publicly available sources, and assessed subsequent screening behaviors using data from the electronic health record. All women had a SDM conversation with the clinician using an online patient decision aid (www.healthdecision. org). These conversations were audiotaped, transcribed, and analyzed for characteristics of SDM.

Groups of patients were further analyzed based on respective clinician background (eg, identity, years in practice) to evaluate how clinician characteristics may shape screening behavior. To meaningfully differentiate 
between clinician levels of experience, we grouped years in practice into 4 ordered categories: $<10$ years, 10-20 years, $21-30$ years, $>30$ years. We calculated two alternative measures of screening behavior for clinicians grouped by years in practice: 1) By averaging the screening rates for the clinicians within each group, and 2) by combining the patients for clinicians within each group and calculating the screening rate for the group. We present results using the second measure, as results were consistent across the two alternative measures.

We performed nonparametric between-group analyses to determine if significant differences in screening behavior existed between groups of patients sharing the characteristics of age, race/ethnicity, previous history of abnormal mammogram, family history of breast cancer, level of household income, and level of education. Chisquared and Kruskal-Wallis tests, as well as logistic regression, were used to assess the differences across groups in the proportion of patients receiving screening mammograms. Post-hoc pairwise comparison (Dunn's test) with Bonferroni correction determined significance between groups, with a statistically significant threshold of $\mathrm{P}<0.05$. Additional chi-squared and Kruskal-Wallis tests were performed to examine the distribution of patient characteristics among clinicians to rule out potential confounds based on differences in patient characteristics.

The study was approved by the University of Wisconsin institutional review board for health sciences research.

\section{RESULTS}

SDM conversations between 54 women 40-49 years of age and 11 different clinicians were analyzed. The patients were predominantly white (51 of 54, (94.4\%), college-educated (39 of 54, 72.2\%), and a slight majority had annual household incomes greater than $\$ 100,000$ (28 of 53, 52.8\%) (Table 1). The 11 clinicians (10 female, 1 male) included 9 physicians and 2 nurse practitioners, ranging in age from 37 to 63 years old and in years of internal or family medicine practice from 9 to 36 (Table 2). Encounter transcriptions revealed no significant differences between providers regarding the characteristics of SDM, and all used the same online decision aid.

Overall, 61\% (33 of 54) of women had a mammogram. Women with a history of a previous abnormal mammogram or a family history of breast cancer were significantly more likely to get a screening mammogram based on the independent tests. However, these differences became nonsignificant following application of the Bonferroni correction, possibly due to the small sample size. Almost $85 \%$ (11 of 13) of patients with a history of an abnormal mammogram had a screening mammogram during the follow-up period compared with $46.4 \%$ (13 of 28 ) of patients without this history (Figure 1). Similarly, 75\% (15 of 20) of women with a family history of breast cancer had a mammogram compared with $51.6 \%$ (16 of 31 ) of patients without family history of breast cancer.

Table 1. Patient Characteristics

\begin{tabular}{|c|c|c|c|c|c|}
\hline Characteristic & Group & $\begin{array}{l}\text { No. in } \\
\text { group }\end{array}$ & $\begin{array}{c}\text { Percentage } \\
\text { screened }\end{array}$ & $\begin{array}{c}\text { Group } \\
\text { differences }\end{array}$ & $P^{*}$ \\
\hline $\begin{array}{l}\text { History of abnormal } \\
\text { mammogram }\end{array}$ & $\begin{array}{l}\text { Yes } \\
\text { No }\end{array}$ & $\begin{array}{l}13 \\
28\end{array}$ & $\begin{array}{l}84.6 \% \\
46.4 \%\end{array}$ & $\begin{array}{c}\mathrm{P}=0.021 \text { on } \mathrm{X}^{2} \\
\mathrm{P}=0.023 \text { on } \mathrm{K}-\mathrm{W}\end{array}$ & 0.138 \\
\hline $\begin{array}{l}\text { Family history of breast } \\
\text { cancer }\end{array}$ & $\begin{array}{l}\text { Yes } \\
\text { No }\end{array}$ & $\begin{array}{l}20 \\
31\end{array}$ & $\begin{array}{l}75.0 \% \\
51.6 \%\end{array}$ & $\begin{array}{c}\mathrm{P}=0.048 \text { on } \mathrm{X}^{2} \\
\mathrm{P}=0.049 \text { on } \mathrm{K}-\mathrm{W}\end{array}$ & 0.294 \\
\hline Patient age & $\begin{array}{l}40-44 \text { years } \\
45-49 \text { years }\end{array}$ & $\begin{array}{l}31 \\
22\end{array}$ & $\begin{array}{l}54.8 \% \\
68.2 \%\end{array}$ & $\begin{array}{c}\mathrm{P}=0.328 \text { on } \mathrm{X}^{2} \\
\mathrm{P}=0.332 \text { on } \mathrm{K}-\mathrm{W}\end{array}$ & $>0.999$ \\
\hline Level of education & $\begin{array}{c}\text { High school/GED } \\
\text { Some college } \\
\text { 4-year college } \\
\text { More than 4-year college }\end{array}$ & $\begin{array}{l}4 \\
11 \\
21 \\
18\end{array}$ & $\begin{array}{l}50.0 \% \\
63.6 \% \\
71.4 \% \\
50.0 \%\end{array}$ & $\begin{array}{c}P=0.549 \text { on } X^{2} \\
P=0.557 \text { on } K-W\end{array}$ & $>0.999$ \\
\hline Household income & $\begin{array}{c}<\$ 40,000 \\
\$ 40,001-\$ 75,000 \\
\$ 75,001-\$ 100,000 \\
>\$ 100,000\end{array}$ & $\begin{array}{c}4 \\
13 \\
8 \\
28\end{array}$ & $\begin{array}{l}25.0 \% \\
61.5 \% \\
62.5 \% \\
67.9 \%\end{array}$ & $\begin{array}{c}P=0.630 \text { on } X^{2} \\
P=0.640 \text { on } K-W\end{array}$ & $>0.999$ \\
\hline Previous breast biopsy & $\begin{array}{l}\text { Yes } \\
\text { No }\end{array}$ & $\begin{array}{c}7 \\
46\end{array}$ & $\begin{array}{l}85.7 \% \\
56.5 \%\end{array}$ & $\begin{array}{c}P=0.141 \text { on } X^{2} \\
P=0.145 \text { on } K-W\end{array}$ & 0.870 \\
\hline
\end{tabular}

*with Bonferroni correction.

$X^{2}$, chi-squared test; $K-W$, Kruskal-Wallis test. 
Table 2. Clinician Characteristics

\begin{tabular}{|c|c|c|c|c|c|c|c|}
\hline Characteristic & Groups & $\begin{array}{l}\text { Degree, } \\
\text { Specialty }\end{array}$ & $\begin{array}{c}\text { No. of } \\
\text { patients }\end{array}$ & $\begin{array}{l}\text { Percentage } \\
\text { screened }\end{array}$ & $\begin{array}{c}\text { Group } \\
\text { differences }\end{array}$ & $\begin{array}{l}\text { Pairwise } \\
\text { comparison }\end{array}$ & $P^{*}$ \\
\hline Years in practice & $\begin{array}{c}<10 \\
11-20 \\
21-30 \\
>30\end{array}$ & $\begin{array}{l}- \\
- \\
- \\
-\end{array}$ & $\begin{array}{l}7 \\
22 \\
15 \\
10\end{array}$ & $\begin{array}{l}57.1 \% \\
77.2 \% \\
26.6 \% \\
80.0 \%\end{array}$ & $\begin{array}{c}P=0.010 \text { on } X^{2} \\
P=0.010 \text { on } K-W\end{array}$ & $\begin{array}{c}21-30 \text { vs } \\
11-20 \\
21-30 \text { vs } \\
>30\end{array}$ & $\begin{array}{l}0.013 \\
0.048\end{array}$ \\
\hline Clinician ID & $\begin{array}{c}1 \\
2 \\
3 \\
4 \\
5 \\
6 \\
7 \\
8 \\
9 \\
10 \\
11\end{array}$ & $\begin{array}{c}\text { NP } \\
\text { DO, Int Med } \\
\text { MD, Int Med } \\
\text { MD, Fam Med } \\
\text { MD, Fam Med } \\
\text { NP } \\
\text { DO, Fam Med } \\
\text { MD, Fam Med } \\
\text { MD, Fam Med } \\
\text { MD, Int Med } \\
\text { MD, Fam Med }\end{array}$ & $\begin{array}{l}6 \\
3 \\
1 \\
7 \\
3 \\
7 \\
3 \\
2 \\
6 \\
7 \\
9\end{array}$ & $\begin{array}{c}100 \% \\
66.7 \% \\
100 \% \\
57.1 \% \\
66.7 \% \\
85.7 \% \\
33.3 \% \\
50.0 \% \\
0 \% \\
85.7 \% \\
44.4 \%\end{array}$ & $\begin{array}{c}P=0.032 \text { on } X^{2} \\
P=0.036 \text { on } \mathrm{K}-\mathrm{W}\end{array}$ & $\begin{array}{l}\text { Clinician } 1 \text { vs } \\
\text { Clinician } 9\end{array}$ & 0.024 \\
\hline
\end{tabular}

*with Bonferroni correction.

$X^{2}$, chi-squared test; Fam Med, family medicine; Int Med, internal medicine; K-W, Kruskal-Wallis test.

Of 7 patients seen by clinicians with $<10$ years of experience, $4(57 \%)$ received mammograms. This compared to $77.2 \%$ (17 of 22 ), $26.6 \%$ ( 4 of 15 ), and $80 \%$ (8 of 10) of patients visiting clinicians with $10-20,21-$ 30 , and $>30$ years of experience, respectively. Significant differences were present between the group of patients seen by clinicians with $21-30$ years of experience as compared to those of clinicians with $10-20$ and $>30$ years of experience (Figure 1).

To rule out alternative explanations that differences in patient characteristics between clinicians account for the differences in screening behavior across groups, we examined the distribution of patient characteristics among clinicians categorized either by family history of breast cancer or patient history of abnormal mammogram. No significant differences in patient characteristics were found $(\mathrm{P}=0.695$ per chi-squared and $\mathrm{P}=0.709$ per KruskalWallis, and $\mathrm{P}=0.768$ per chi-squared and $\mathrm{P}=0.782$ on Kruskal-Wallis, respectively).

As a robustness test, a logistic regression analysis was run, with screening rate as the dependent variable and years in practice as the independent variable. As there were 4 ordered categories for years in practice, $>30$ years in practice was defined as the baseline group. The overall model was found to be significant $\left(\chi^{2}: 11.622 ; \mathrm{P}=.009\right.$; log-likelihood ratio: 60.548). Additionally, the overall variable of years in practice was found to be significant $(\mathrm{P}=0.018)$. In terms of the years in practice categories, the coefficient for $21-30$ years in practice was significant (odds ratio: 0.091; $\mathrm{P}=0.015$ ); as the reference group was clinicians with $>30$ years in practice, this coefficient represents the difference between those with $21-30$ vs $>30$. These results were consistent with the chi-squared and Kruskal-Wallis results.

Another logistic regression analysis that incorporated years in practice as a continuous variable found no significant results $\left(\chi^{2}: 0.347 ; \mathrm{P}=0.556 ; \log\right.$-likelihood ratio: 71.824), which lends support for grouping years in practice to meaningfully differentiate between clinicians' levels of experience.

\section{DISCUSSION}

SDM is by definition a patient-centered technique ${ }^{5}$ and relies on patient beliefs and values. Our study of women who all had structured SDM conversations with their clinicians about breast cancer screening using the same online patient decision aid demonstrated differences in screening rates based on patient characteristics. However, significant differences in screening rates also were noted based on which clinician was seeing the patient. Screening behaviors varied widely across individual physicians, which raises the question of whether physician preference/values, rather than patient preference/values, might have been the driving force for whether or not the patient ultimately underwent mammography. Research has documented that clinician attitudes predict screening rates of their patients, but such an outcome is antithetical to the intended concept of SDM. ${ }^{6}$

Clinician attitudes may vary depending on the clinical scenario and the evidence behind the intervention. ${ }^{7}$ Two 


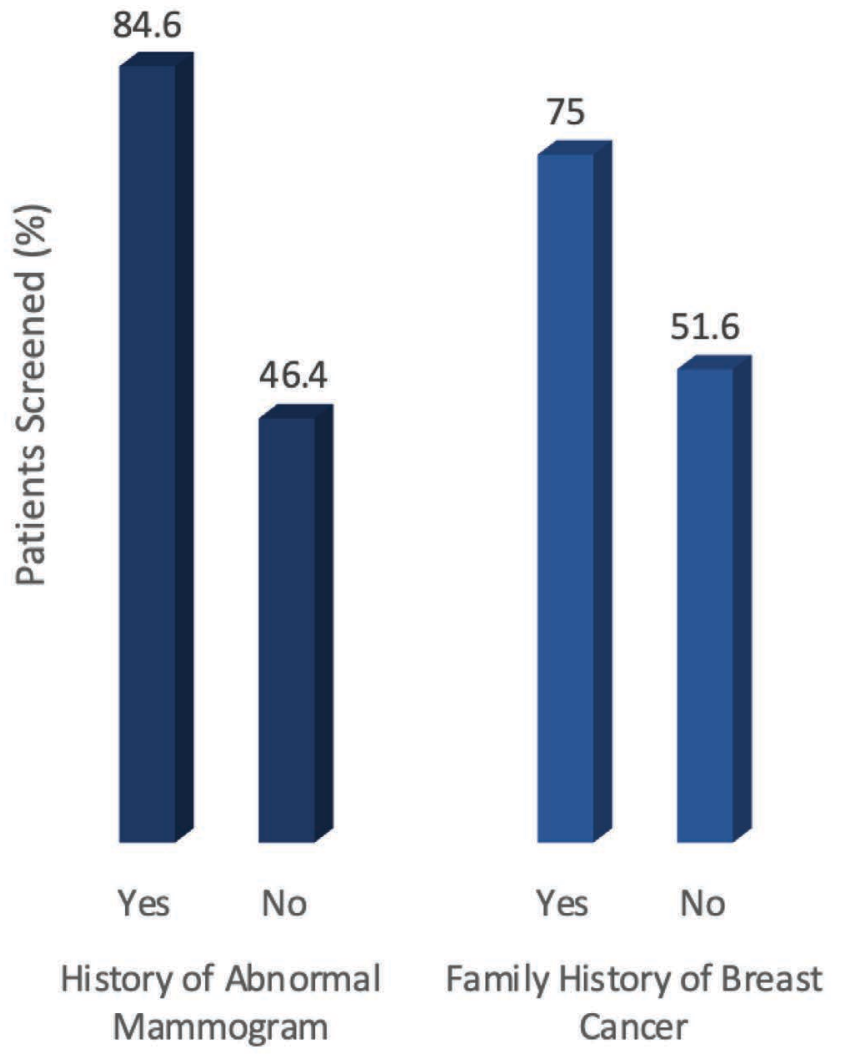

studies that evaluated screening rates of primary care clinicians in the Midwest found variable screening rates by clinicians. ${ }^{2,3}$ Both studies also found that nonphysician clinicians (ie, nurse practitioners or physician assistants) tended to have higher rates of recommended screening than their physician colleagues. ${ }^{2,3}$ The science behind how primary care providers decide whether or not to recommend screening is complicated and variable. Both patient and provider variables can affect screening decisions, as can individual perceptions of screening study efficacy. ${ }^{8}$ Our study demonstrated variations in screening rates within a context of a known SDM conversation and use of a decision aid. The goal of decision aids is to standardize SDM conversations and take clinician bias out of the equation. ${ }^{9}$

Limitations of this study include a small sample size (54 women, 11 clinicians) and lack of diversity in the patient sample, which was biased toward White, educated women. However, all clinicians used a standardized tool, minimizing practice variability, so we feel that our results are still valid. It is possible that some women preferentially choose clinicians who have similar attitudes toward screening as themselves, which may have introduced further bias.

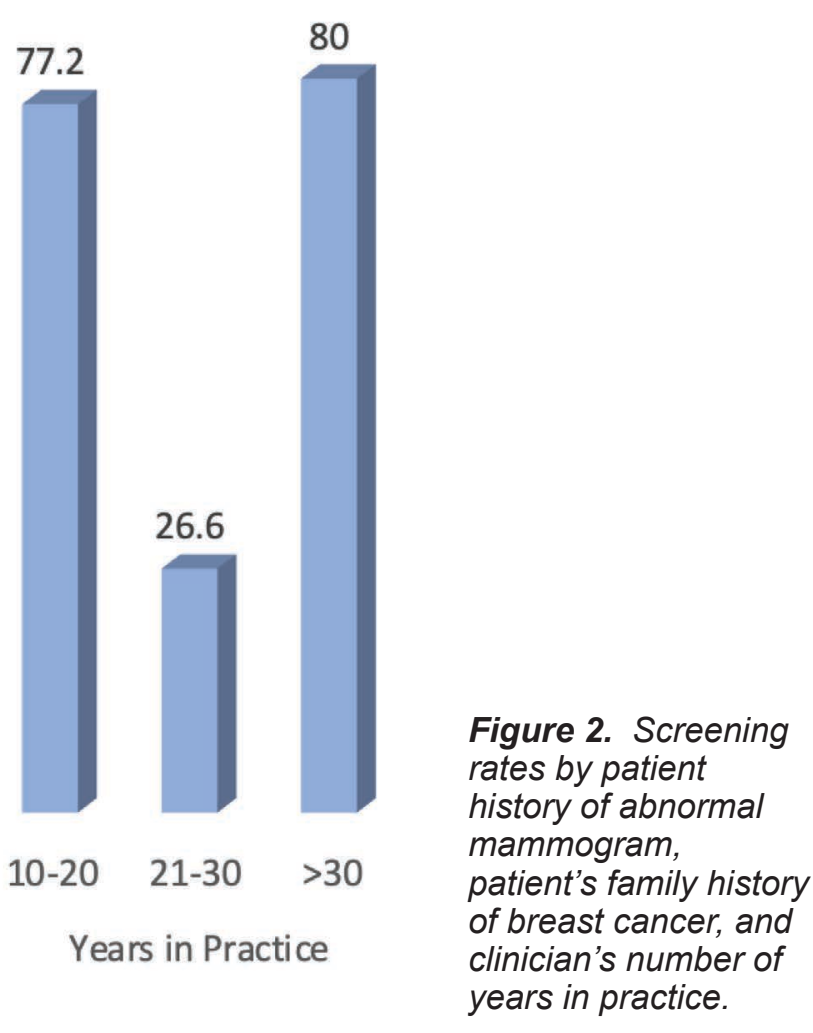

Our findings that women with history of an abnormal mammogram and family history of breast cancer had higher screening rates reinforce prior literature. The overall study results raise important issues regarding clinician training in shared decision-making that should be a focus for future research.

\section{Patient-Friendly Recap}

- A clinical approach of "shared decision-making" is recommended when discussing the pros and cons of breast cancer screening with women in their 40s.

- Authors investigated whether certain patient or clinician features predict which patients will choose to subsequently receive a mammogram.

-While women with a prior abnormal mammogram result or family history of breast cancer more frequently opted for screening, rates also varied widely between clinicians, indicating clinician attitudes may have overly impacted the decisionmaking conversation. 


\section{Author Contributions}

Study design: Schrager, Little, DuBenske, Burnside. Data acquisition or analysis: Schrager, Evaristo. Manuscript drafting: Schrager, Evaristo. Critical revision: Schrager, Little, DuBenske, Burnside.

\section{Conflicts of Interest}

None.

\section{Funding Sources}

This work was supported by the community-academic partnerships core of the University of Wisconsin Institute for Clinical and Translational Research, the National Center for Advancing Translational Sciences (grant number 9 U54 TR000021, and previous grant number 1 UL1 RR025011 from the National Center for Research Resources), the National Cancer Institute of the National Institutes of Health (grant number K24 CA194251), and the University of Wisconsin Carbone Cancer Center (support grant number P30 CA014520). The content is solely the responsibility of the authors and does not necessarily represent the official views of the National Institutes of Health or other funders.

\section{References}

1. U.S. Preventive Services Task Force. Final recommendation statement. Breast cancer: screening. Published January 11, 2016; accessed July 8, 2020. https://www.uspreventiveservicestaskforce. org/uspstf/recommendation/breast-cancer-screening

2. Nachtigal E, LoConte NK, Kerch S, Zhang X, Parkes A. Variation in breast cancer screening recommendations by primary care providers surveyed in Wisconsin. J Gen Intern Med. 2020;35:2553-9. CrossRef
3. Martin K, Vogel RI, Nagler RH, et al. Mammography screening practices in average-risk women aged 40-49 years in primary care: a comparison of physician and nonphysician providers in Minnesota. J Womens Health (Larchmt). 2020;29:91-9. CrossRef

4. Martínez-Alonso M, Carles-Lavila M, Pérez-Lacasta MJ, Pons-Rodríguez A, Garcia M, Rué M; InforMa Group. Assessment of the effects of decision aids about breast cancer screening: a systematic review and meta-analysis. BMJ Open. 2017;7(10):e016894. CrossRef

5. Bomhof-Roordink H, Gärtner FR, Stiggelbout AM, Pieterse AH. Key components of shared decision making models: a systematic review. BMJ Open. 2019;9(12):e031763. CrossRef

6. Radhakrishnan A, Nowak SA, Parker AM, Visvanathan K, Pollack CE. Linking physician attitudes to their breast cancer screening practices: a survey of US primary care providers and gynecologists. Prev Med. 2018;107:90-102. CrossRef

7. Hsu C, Liss DT, Frosch DL, Westbrook EO, Arterburn D. Exploring provider reactions to decision aid distribution and shared decision making: lessons from two specialties. Med Decis Making. 2017;37:113-26. $\underline{\text { CrossRef }}$

8. Siedlikowski S, Ells C, Bartlett G. Scrutinizing screening: a critical interpretive review of primary care provider perspectives on mammography decision-making with averagerisk women. Public Health Rev. 2018;39:15-35. CrossRef

9. Stacey D, Légaré F, Lewis K, et al. Decision aids for people facing health treatment or screening decisions. Cochrane Database Syst Rev. 2017;4(4):CD001431. CrossRef

(C) 2021 Advocate Aurora Health, Inc. 